\title{
The role of phytopathogenicity in bark beetle-fungus symbioses: A challenge to the classic paradigm
}

\author{
Diana L. Six ${ }^{1}$ and Michael J. Wingfield ${ }^{2}$
}

(1) Department of Ecosystem and Conservation Sciences, College of Forestry and Conservation, The University of Montana, Missoula, Montana 59812.

(2) Forestry and Agricultural Biotechnology Institute, University of Pretoria, Pretoria, Republic of South Africa 0002.

Diana L. Six

Email: diana.six@cfc.umt.edu

\begin{abstract}
The idea that phytopathogenic fungi associated with tree-killing bark beetles are critical for overwhelming tree defenses and incurring host tree mortality, herein called the classic paradigm (CP), has driven research on bark beetle-fungus symbiosis for decades. It has also strongly influenced our views of bark beetle ecology. We discuss fundamental flaws in the CP, including the lack of consistency of virulent fungal associates with tree-killing bark beetles, the lack of correspondence between fungal growth in the host tree and the development of symptoms associated with a successful attack, and the ubiquity of similar associations of fungi with bark beetles that do not kill trees. We suggest that, rather than playing a supporting role for the host beetle (tree killing), phytopathogenicity performs an important role for the fungi. In particular, phytopathogenicity may mediate competitive interactions among fungi and support survival and efficient resource capture in living, defensive trees.
\end{abstract}

\section{Introduction}

It has been more than 100 years since Von-Schrenk (107) first noted that trees killed by bark beetles often became stained by fungi within a few weeks of attack. Likewise, 80 years have passed since Craighead (24), observing this same relationship, speculated that the fungi may play an important role in the death of bark beetle-attacked trees or in the nutrition of the beetles. Although the latter possibility has received some attention over the years, the concept that tree-killing bark beetles require fungal pathogens to overcome tree defenses and to incur tree mortality has received the most attention. This hypothesis, which we hereafter refer to as the classic paradigm (CP), has formed the basis for the majority of research conducted on these interactions. However, despite numerous studies, no conclusive evidence exists supporting the CP. The common and selfperpetuating practice of citing the $\mathrm{CP}$ as fact in the literature has also meant that the $\mathrm{CP}$ is seldom questioned. As a result, few alternative hypotheses are considered when research is conducted on these systems.

In this review, we question the validity of the CP. That some tree-killing bark beetles possess virulent fungal associates is not in question. It is well known that some do and that some of these fungi are capable of killing trees $(20,46,102,114)$. It is also not in question whether fungi elicit defensive reactions in conifers; an extensive literature exists documenting the form and process of these responses (29). Rather, we question the view that the fungi play a proximate role in aiding 
bark beetles to overwhelm trees. We hope this review provokes thought and initiates new avenues of investigation into these fascinating and complex interactions.

At the outset we provide a brief review of bark beetle-fungus associations. The focus here is primarily on conifer-infesting bark beetles, specifically because the $\mathrm{CP}$ arose from studies on these systems. For more in-depth treatments of these symbioses, we refer readers to several recent reviews $(32,47,88,91)$. Next, we describe the process of attack and colonization of trees by bark beetles. We then present evidence and arguments for and against the CP. Finally, we propose alternative explanations for the occurrence of phytopathogenicity in bark beetle-associated fungi and suggest some directions for future research.

\section{Bark beetle-fungus symbioses}

Bark beetles (Curculionidae: Scolytinae) construct galleries under the bark in the phloem layer of woody plants, where they lay eggs and their brood feed and develop (Figure 1). Most are limited to colonizing weak or recently killed trees; however, a few species are capable of killing healthy trees or developing in living trees without causing mortality (113).

One of the most striking characteristics of bark beetles is their widespread association with fungi ( 8 , 47, 88). Most species carry fungi, either in specialized structures of the integument called mycangia or phoretically on the exoskeleton (87).Most fungal partners are Ascomycetes in four sexual genera, Ophiostoma, Ceratocystiopsis, Grosmannia, and Ceratocystis (32, 33, 43, 47, 88, 111, 117). Ophiostoma, Grosmannia, and Ceratocystiopsis form a monophyletic group in the Ophiostomatales separate from Ceratocystis, which resides in the Microascales (103). A small number of bark beetles are also associated with Basidiomycetes in the genera Entomocorticium and Phlebiopsis $(42,108)$.

There has been a tendency to view all bark beetle-fungus symbioses as similar in function. However, there is actually a diversity of interaction types. Fungal associates benefit from the association through transport to ephemeral and otherwise inaccessible plant resources. Introduction into living or recently killed trees may also allow these fungi to avoid competition with later successional saprophytic fungi. Effects on the bark beetle host vary from beneficial to neutral to negative (88).Many of these associations are thought to be mutualisms based on the phytopathogenicity of the fungi (the $\mathrm{CP}$ ). This idea is developed in subsequent sections. In contrast, a number appear to be obligate mutualisms in which the bark beetles rely on nutritional supplementation from fungi $(5,11,15,23,93)$. At least some mutualistic partners exhibit parallel cladogenesis with their hosts, indicating long coevolutionary histories $(87,93)$. In these associations, larvae that feed on phloem colonized by mutualistic fungi are larger, more likely to complete development, have higher fecundity, and develop more rapidly than bark beetles that do not $(5,11,23,93)$. For at least one bark beetle species, feeding on fungal spores by new adults appears to be required for reproduction (93). Alternatively, some bark beetle-fungus mutualisms may be facultative, with hosts benefiting from feeding on fungi but not requiring it for survival (28, 54).

Some associations, especially those involving incidental fungi, are likely to be commensalisms with no measurable effect on the bark beetle host. In contrast, some fungi have strong negative effects on bark beetle development and survival $(6,37)$. The underlying cause of antagonism is not known but may be related to the inability of a fungus to provide critical nutrients (53). Whether a fungus is beneficial, commensal, or antagonistic is not strictly linked to taxonomy; fungi involved in all three types of relationships with bark beetles can be closely related congenerics. For example, two sister species interact with their hosts in different ways: Ophiostoma montium is a highly specific nutritional mutualist with Dendroctonus ponderosae (mountain pine beetle) (93), whereas Ophiostoma ips is considered a commensal with many bark beetles worldwide $(83,116)$. 
Bark beetles carry complexes of fungi $(44,47,57)$. Most of this diversity consists of incidental fungi likely to be of no importance to the insect host because of their variable and often low incidence. The symbiotic fungi (consistent associates) are less diverse and often include only two to three partners per bark beetle species. These partners can have either differing or redundant effects. For example, Dendroctonus frontalis (southern pine beetle) possesses three main associates, two nutritional mutualists, and one antagonist $(6,37)$.

While the general membership of the symbiont community associated with a host may remain constant, or nearly so, the relative prevalence of each symbiont may vary considerably over time and within and among locations $(39,44,90,104)$. This variability is due primarily to differences in the tolerances of the fungi to various environmental conditions. In nature, these differences translate to changes in the relative prevalence and competitiveness of each fungus, and thus its influence on the host, as conditions shift over time. For example, the two fungi associated with $D$. ponderosae (one cold tolerant, the other heat tolerant) shift in their relative prevalence on dispersing hosts as temperatures fluctuate over a season (90). Grosmannia clavigera dominates during cooler periods, but $O$. montium is dominant during warmer periods. Similar effects of temperature on fungal symbiont prevalence have also been observed in the $D$. frontalis system (38). Differences in fungal preferences for phloem or sapwood are likely dictated largely by different nutritional requirements and enzymatic capabilities (2).

Differences in virulence, in tolerances to host tree defensive chemistry, and in moisture and oxygen requirements also influence which fungus dominates and when $(3,12,13,44,48,97)$. The tree, as a resource for both fungi and bark beetles, changes considerably from the time of attack to the time when brood beetles emerge, often as long as one year later. At the time of attack, conditions are conducive to the proliferation of pathogens. However, over time as defensive compounds dissipate, tissues dry, oxygen increases, and nutritional content declines, conditions become more suitable for saprophytes $(3,12,13,44)$. As conditions within a tree change, so will the ability of a given fungus to grow and capture resources $(48,53)$. Depending on the particular requirements of a fungus, it may be optimally suited to the early, middle, or late stage of tree colonization, but not to conditions occurring over the entire period. Variability in local weather conditions, particularly precipitation and temperature, adds an additional layer of stochasticity to the structure of the symbiont community.

In summary, symbiont communities associated with bark beetles are diverse and dynamic, with variable structures strongly influenced by their environment. Although highly dynamic, many have likely been shaped and fine-tuned by long periods of coevolution.

\section{Bark beetle colonization of a tree}

Trees are not sitting ducks, but rather possess elaborate defense systems that function to protect them from a plethora of insects and pathogens. These include preformed defenses, in place regardless of whether an attack occurs, and induced defenses, which form only in response to attack $(9,29)$. Many bark beetles colonize recently killed or severely compromised trees. For these insects, tree defenses are of trivial concern as defenses in such trees are low to lacking. However, for bark beetles that attack, and kill healthy trees, overcoming host defenses is paramount for survival and reproduction. This is a matter of kill or be killed. The general attack, colonization, and developmental sequence for a tree-killing bark beetle and its associated fungi is presented in Figure 1 . 


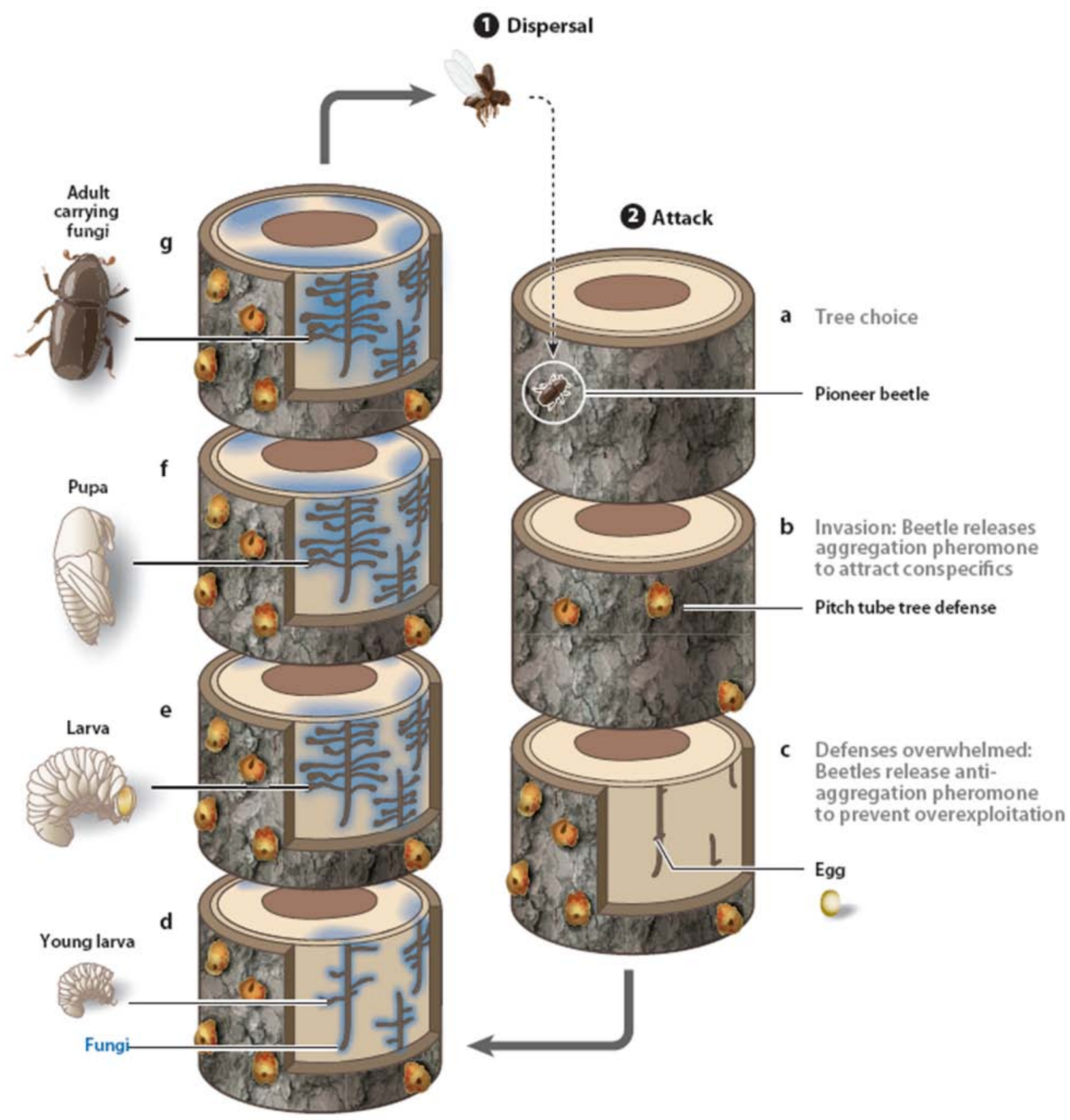

(3) Colonization

Figure 1. Generalized life cycle of a tree-killing bark beetle and its associated fungi. (1) Dispersal of adult beetles carrying fungi in mycangia and/or on exoskeleton. (2) Attack phase. (a) Tree choice by pioneer (first arriving) beetle. (b) Entry into tree and subsequent release of aggregation pheromones. Conspecifics of both sexes are attracted to the pheromone, enter the tree, and release additional pheromone. The pheromone-mediated mass attack typically occurs over a relatively short period (often 2-5 days). In some conifers, pitch tubes form as part of preformed defenses. (c)When tree defenses are overwhelmed (the point of no return), beetles switch from producing aggregation to antiaggregation pheromones to avoid overexploitation of the tree. (3) Colonization phase. (d) Initial egg gallery construction by parental adults, egg-laying, and inoculation of fungi into phloem. During the early stages of development of beetle larvae, there is low vertical spread of vegetative (hyphal) growth of fungi in phloem, and the beginnings of hyphal penetration into sapwood. Tree defensive chemistry and moisture levels are high and oxygen availability is low, limiting the growth of fungi at this stage. (e) Extensive larval tunneling. Phloem and sapwood begin to dry and defensive chemistry has declined, allowing extensive hyphal colonization by fungi. $(f)$ Excavation of pupal chambers and pupation. Fungi begin to form spore layers in pupal chambers. $(g)$ Spore feeding by teneral (newly emerged) adults, acquisition of fungi in mycangia or on exoskeleton. 
The killing of a tree is initiated through a pheromone-mediated mass attack (112). The number of bark beetles are required to kill a tree in an attack varies depending on the vigor of the tree $(21,67$, 76). In general, the more vigorous a tree, the more bark beetles are required to overcome its defenses $(9,19,76)$. The sequence of a mass attack begins with a single bark beetle arriving at a tree and releasing an aggregation pheromone that attracts conspecifics of both sexes from the surrounding area. Arriving bark beetles, in turn, release additional pheromones that increase the attractive signal and the likelihood of a successful attack (112).

The first obstacle bark beetles encounter is the preformed conifer defense system, which in conifers consists primarily of resin released as bark beetles bore into the tree $(9,29)$. Resin acts as a physical barrier to entry by repelling, and often drowning, bark beetles and can effectively halt an attack. However, if enough bark beetles are recruited within a sufficiently short time frame, resin can be depleted, allowing bark beetles access to the phloem layer beneath the outer bark. At this point, bark beetles may still have to contend with induced defenses $(9,29)$. In conifers, these consist of lesions that form in the immediate area surrounding the bark beetle. Lesions contain high concentrations of secondary chemicals, which can be toxic to the insects and halt the growth of symbiotic fungi (66, 80). A strong induced defense can end an attack, in which case the tree survives. When trees are overwhelmed, either no induced defense forms or it is terminated before bark beetle attack ceases. Note that we do not state that the tree dies at this point, merely that it reaches a point of no return where the eventual death of the tree is assured. This point occurs rapidly. In fact, the entire sequence of events, from the initiation of attack to the point of no return for a tree, typically occurs over just a few days $(4,58,76,98)$. Beetles appear able to detect when the point of no return occurs. Here, they respond accordingly by switching to releasing repellant antiaggregation pheromones that act to halt the attack $(76,112)$.

For more information on defense responses of conifers, we refer readers to reviews by Paine et al. (70), Lieutier (59), and Franceschi et al. (29). For additional information on the colonization sequence of trees by tree-killing bark beetles, readers are directed to the review by Raffa et al. (77).

\section{The classic paradigm}

Broadly stated, the $\mathrm{CP}$ postulates that fungi associated with bark beetles play a critical role in overwhelming tree defenses and causing tree death. Two divergent hypotheses have been proposed: the tree killing hypothesis and the defense exhaustion hypothesis. The first hypothesis suggests that colonization of the tree by virulent fungi leads directly to tree death, primarily by blocking water conduction in the xylem $(56,70)$. The fungi do not appear to produce toxins $(25,34)$. The second hypothesis proposes that fungi lead indirectly to tree death by stimulating induced defenses in the phloem, which ultimately results in their exhaustion, allowing bark beetles to invade (60).

Both hypotheses have been tested primarily using artificial inoculations of living trees with symbiotic fungi; however, how the results of such studies are interpreted varies depending on the hypothesis. Studies employing low numbers of inoculations to living trees have been used to assess the length of lesions that result from fungal colonization of the phloem. Under the tree killing hypothesis, lesion length is used as a proxy for virulence and longer lesions are assumed to be produced by more virulent associates $(64,65,80,82)$. In this context, lesion length is used to assess the relative value of each fungus to the bark beetle. The fungal partner of a bark beetle that produces the longest lesion is considered to be the most virulent and thus the most beneficial because it is most likely to contribute to the death of the tree $(102,115)$. However, some symbionts are better suited to growth in phloem, whereas others are more aggressive in colonizing sapwood $(52,96)$. Because blockage of sapwood conduction is thought to be the primary mechanism by which the fungi incur tree death, assessments of sapwood penetration as well as measurements of lesion development are critical $(14,20,41,46,74,85,102)$. 
Under the defense exhaustion hypothesis, which postulates that the primary role of the fungi is to exhaust tree defenses, fungal activity in phloem is vital because induced defenses are initiated and form in tree phloem. Therefore, in this case, lesion length becomes the critical measure (60). Under this hypothesis, virulence of the fungus (ability to penetrate sapwood and block water conduction) is of minimal to no importance (60).

High-density inoculations have been used to investigate the tree killing hypothesis. In these studies, trees are inoculated with fungi at high densities (similar to those occurring under natural attack, or often,much higher densities) $(46,85,102)$. The trees are then assessed weeks to months later for reductions in water conduction or mortality $(14,20,41,74)$.

\section{Difficulties Testing the CP}

The CP remains controversial because it is difficult to test directly through experimentation. The choice of a tree, and its subsequent attack and colonization by bark beetles and fungi, is a complex process and not one easily replicated in experiments. The cues used by bark beetles to choose an appropriate host are not known; thus, trees chosen by humans may or may not be those most suitable for attack. The logistics of both inoculating and punching holes into trees in a way that mimics bark beetle attack is daunting, especially when one factors in timing, the number of required treatment levels and replication, and the need for positive and negative controls. Such studies still lack other important factors that may influence a tree reaching the point of no return in a biologically meaningful way. These include proper dose of mimicked attacks to match the vigor of the tree and the effects of adult and larval tunneling (and consequently, effects of oxygen and moisture on fungi growth and the extent of their distribution within the tree). The fact that we have no way of precisely determining when the point of no return occurs, and that tree death is not a discrete event but rather one that occurs by compartment over an extended period, regardless of causal agent (27), is also problematic when it comes to assessing outcomes of our experiments.

Because of these and other difficulties in directly testing the $\mathrm{CP}$, we have taken a more indirect approach to assess its validity. In the next section, we develop several arguments that show, alone and in combination, that the $\mathrm{CP}$ is fundamentally flawed.

\section{Arguments against the classic paradigm}

\section{Tree-killing bark beetles can kill trees without virulent pathogens}

Perhaps the most compelling argument against the role of fungi in killing trees is that tree killing bark beetles can and often do kill trees in the absence of virulent pathogens. Most bark beetles are associated with more than one symbiotic fungus $(44,47,88,104)$. For tree-killing bark beetles that possess virulent associates (not all do), typically only one associate exhibits this characteristic and the prevalence of this associate in a population can vary considerably. Such variability is inconsistent with a critical direct role of fungi in tree killing. Under the $\mathrm{CP}$, populations lacking the virulent associate would move rapidly toward extinction because they would not be able to kill trees. The success of a population would depend on the relative prevalence of the virulent fungus. If present with all or most bark beetles, the population should be robust and perhaps even expand. In contrast, when prevalence is low, populations should decline, and if environmental conditions do not shift rapidly in a manner to increase the prevalence of the virulent associate, those populations should also move rapidly toward extinction.

However, this is not what we observe. The first observations that trees can be killed by bark beetles in the absence of a virulent pathogen were made by Hetrick (35) and Bridges et al. (17). These authors observed pines that had been killed by D. frontalis but that were lacking Ophiostoma minus, 
the only pathogenic fungus commonly associated with this beetle. This phenomenon has subsequently been observed for Dendroctonus brevicomis (109). Another example is Ips typographus, the most serious killer of spruce in Europe. This beetle is associated with Ceratocystis polonica, a highly virulent pathogen capable of killing trees, and with several other weakly virulent or nonpathogenic fungi $(44,47)$. Because of its virulence, $C$. polonica is thought to be critical in causing tree mortality. However, the prevalence of this fungus with the beetle is highly variable, as it is found commonly in some portions of the host's range but only rarely or not at all in others (44, $47,55,86,95,104,105)$. Yet, even in populations where the fungus is rare or apparently lacking, the bark beetle kills trees and is capable of developing outbreaks. Likewise, with $D$. ponderosae (the most serious pest of pines in the western United States and Canada) the presence of its more virulent associate is not required for tree death or the development of epidemics $(88,90)$.

Yet another example is Dendroctonus rufipennis (spruce beetle), which vectors Leptographium abietinum and Ceratocystis rufipenni. Ceratocystis rufipenni is highly virulent and thus under the CP has been postulated to be an important mutualist (102). L. abietinum, on the other hand, is only weakly pathogenic, and its importance to the bark beetle has thus been downplayed. However, $L$. abietinum is by far the most prevalent fungus with this beetle $(30,81,89)$. It is present with greater than $90 \%$ of bark beetles in all populations thus far surveyed (inclusive of most of its geographic range), whereas C. rufipenni is apparently lacking in most populations and is usually rare in those where it does occur $(30,81,89)$. Although most D. rufipennis populations lack a virulent fungus, they remain capable of killing trees and causing extensive mortality whenever conditions support increases in bark beetles.

From an evolutionary perspective, the inconsistency of association of virulent fungi with their host bark beetles poses a severe dilemma for bark beetles under the CP. If a bark beetle required a virulent pathogen to overcome tree defenses and/or incur tree mortality, it would be inherently risky for it to enter a tree without carrying such a fungus. Any bark beetle without such a fungus would have an increased risk of being killed by the tree and of not reproducing with subsequent strong negative effects on fitness. This should result in strong selection pressure to maintain a highly consistent association with the virulent fungus. As previously noted, the virulent associates of aggressive bark beetles are actually some of those least consistently present. This suggests that if they benefit bark beetles at all through phytopathogenicity, it is a facultative effect at best. In fact, trees develop more pronounced induced defense responses when challenged by virulent associates. This finding suggests that that their association with a bark beetle may actually increase risk during attack, potentially decreasing the fitness of these bark beetles relative to those that enter carrying less virulent associates. Indeed, Raffa \& Smalley (78) found that the presence of virulent bark beetle-associated fungi causes the accumulation of allelochemicals in trees in concentrations that adversely affect bark beetles.

Inconsistency of association also poses problems for the defense exhaustion hypothesis. Under this hypothesis, the presence of fungi that cause the most rapid and extensive stimulation of the induced defense is critical. If defenses are not exhausted rapidly, bark beetles are killed or repelled. Therefore, there should be a close correspondence between a bark beetle's aggressiveness and the ability of their main associated fungal species to rapidly stimulate the defenses of the host tree (60). However, in most systems this close correspondence does not occur. For example, the most consistent associates of $D$. rufipennis, $D$. brevicomis, and $D$. frontalis do not stimulate much in the way of an induced defense $(69,71,72,85)$, yet trees are still killed.

It has been proposed that a lack of consistency of association between a bark beetle and a single fungus highly efficient at stimulating defenses may be compensated for by the complex of fungi often carried by a bark beetle (60). It is true that most bark beetles are associated with a complex of fungal species, some of which can stimulate defenses. However, given that most fungi in such 
complexes are highly incidental and often present on only a low proportion of dispersing bark beetles in a population, the reliance of a bark beetle on such an undependable and variable group of fungi to fulfill such a critical function seems unlikely.

Although much has been made of the ability of some fungi associated with bark beetles to kill trees, few are capable of doing so. In most inoculation studies, trees survive inoculation with bark beetle symbiotic fungi $(51,102)$ unless inoculations have been done at high densities, with unnaturally high inoculum loads, or both $(26,47,85)$.

\section{The point of no return of the tree is not coincident with fungal colonization of tree tissues}

For fungi to be the proximate cause of bark beetle attack, their successful growth in tree tissues and effects on tree function must occur within a short time frame. However, all studies indicate that fungi grow slowly within trees, especially during the critical initial stage of bark beetle colonization $(36,84,98)$ (Figure 1). Likewise, effects on water conduction are not manifest until bark beetle brood development is substantially advanced $(14,115)$.

A successful attack on a tree is often complete within just a few days, and oviposition and brood development occur immediately thereafter $(4,76)$. Fungal colonization, however, occurs at a much slower rate. In some cases, particularly with less virulent associates, fungal growth is initially limited by high moisture and low oxygen (100). For more virulent associates, growth occurs more rapidly, but still relatively slowly compared with colonization of the tree by bark beetle hosts. For example, the fungal associates of I. typographus penetrate the sapwood to a depth of only about 20 $\mathrm{mm}$ after 4-5 weeks, a time when bark beetle larvae have nearly completed their development (98).

This slow rate of penetration indicates that any effect fungi have on conduction in the tree occurs long after trees have been overwhelmed, not before. In fact, effects on conduction may not be due wholly to fungal proliferation. Hobson et al. (36) found that fungal penetration of sapwood follows sapwood occlusion rather than preceding it. In any case, a substantial amount of sapwood must be affected relatively rapidly to induce the symptoms associated with bark beetle attack within a meaningful time frame. Vite (106), extrapolating from experimental work, estimated that more than two-thirds of the sapwood would need to be rapidly disrupted to cause symptoms in trees in a time frame similar to those which occur with bark beetle attack. In the case of bark beetle-associated fungi, growth in trees, even by virulent associates, occurs much too slowly to match this time frame. In fact, at natural attack densities, symbiotic fungi take several months to achieve similar effects, if they occur at all $(73,99)$. This contradiction in fungal colonization rate relative to the development of bark beetle brood and tree symptoms has been previously noted $(60,70)$ and has proven to be one of the most difficult dilemmas to resolve under the tree killing hypothesis.

From these studies, we can see that fungal colonization of tree tissues begins in earnest only after the point of no return has been reached and when bark beetle establishment is well underway. Thus, fungal colonization follows bark beetle colonization, not vice versa. Although some bark beetleassociated fungi are virulent, and a few have been shown to be capable of killing trees in inoculation studies, this virulence may not be biologically meaningful in the context of overwhelming tree defenses and causing tree death. Due to the slow growth rate of bark beetleassociated fungi within trees during the critical attack phase, fungus-caused mortality or a reduction in tree defenses would occur much too late to be of benefit to the insects. The phytopathogenicity exhibited by some of these fungi may play a different role as discussed below. 


\section{The distribution of virulent fungal associates is not correlated with bark beetle aggressiveness}

Under the $\mathrm{CP}$, one would predict that virulence in fungal associates would correlate with bark beetle life history; tree-killing beetles would possess virulent pathogenic fungal associates. Likewise, bark beetles that do not kill trees would have either no fungal associates or only incidental ones lacking virulence. However, this pattern is not observed in nature. For many aggressive bark beetles, the most consistent associates are nonpathogenic or weak pathogens. These include most of the obligate mycangial fungi involved in nutritional symbioses $(40,47,69,88,91)$. In contrast, virulent fungi can often be found with bark beetles that do not typically kill trees. For example, Dendroctonus murrayanae (lodgepole pine beetle), D. terebrans (black turpentine beetle), and D. valens (red turpentine beetle) complete development in living trees (113). Although these beetles do not kill their tree hosts, they are often associated with Leptographium terebrantis, a fungus that is among the most virulent of all Ophiostomatales associated with bark beetles $(7,28,45,50,64,79,110)$. Likewise, $L$. wingfieldii is highly virulent to pines $(45,64)$ but is carried by Tomicus piniperda (pine shoot beetle), which typically infests shoots without killing the host tree.

\section{Non-tree-killing bark beetles also have fungal associates}

The CP arose from observations on tree-killing bark beetle systems, and it is on these systems that virtually all research has focused. However, tree killing is a rare strategy and not representative of the life histories of the vast majority of bark beetles. Worldwide, fewer than fifteen of the thousands of bark beetle species can be considered aggressive tree killers. Many, if not most, non-tree-killing species also possess ophiostomatoid fungal associates. This begs the question of why non-treekilling bark beetles possess fungi similar to those associated with tree-killing bark beetles if they do not need them to kill trees. The presence of these fungi, as well as mycangia, with some non-treekilling species indicates that for at least some species the fungi are important and likely play a role or roles other than those postulated under the CP. Unfortunately, little is known about these symbioses because they do not involve economic pests. For this reason, they have not engendered much interest from the forest entomology community. However, to avoid error due to bias in sampling from forming the basis for the hypotheses we use to investigate these systems, we need to study the composition and function of these symbioses over the entire range of bark beetle life strategies.

\section{Lessons learned from the Dendroctonus frontalis-fungus system}

The best studied of all bark beetle-fungus symbioses is the D. frontalis system. Dendroctonus frontalis is the most important pine-killing species in the southern United States. In this region, the bark beetle is associated with three fungi. Two of these, Ceratocystiopsis ranaculosus and Entomocorticium sp. A, are specific to the bark beetle and carried consistently in mycangia (49). Both fungi appear coevolved with their host (94).Neither of these fungi is phytopathogenic, and defensive responses by the tree to them are minimal (40). Therefore, neither is capable of killing the tree, nor are they likely to contribute in any substantial way to the exhaustion of tree defenses. The third fungus, $O$. minus, is never carried in mycangia, but instead loosely and less consistently on the exoskeleton (49). In addition, this fungus is not specific to the bark beetle, as it is found with many bark beetles including species that colonize weakened, dying, or dead trees $(47,64,101)$. This fungus initiates a moderate induced defense response in pines $(22,40,51,75)$.

Because of its pathogenicity, O. minus was long considered a critical mutualist of $D$. frontalis (14, $24,68)$, overshadowing the beneficial nutritional roles of the mycangial fungi $(5,6,15,23)$. Gradually, however, perceptions of the relative importance and roles of the three fungi with their 
bark beetle host began to shift. Notably, observations that $O$. minus was not always present, or present only in small amounts, in trees killed by $D$. frontalis brought into question the role of this fungus in tree killing. Furthermore, inoculation studies indicated that $O$. minus is not capable of killing mature pines (51). Perhaps most revealing were observations that tunneling larvae of $D$. frontalis turn away from phloem colonized by $O$. minus and do not survive when they cannot avoid feeding in $O$. minus-colonized areas $(6,63)$. Together, these studies and observations suggested that not only is $O$. minus not responsible for overwhelming the tree, it is not a mutualist, but rather an antagonist.

Ironically, the notion that $O$. minus is a mutualist has remained firmly entrenched, and this has led to attempts to reconcile the antagonistic effects of the fungus with the CP. For example, it has been suggested that $O$. minus acts as a mutualist early in the colonization of a tree by aiding the bark beetle in overwhelming tree defenses, but that once the tree is overcome, the fungus acts as an antagonist during larval development $(49,54)$. This shift in roles by the fungus over a single insect generation has been presented as an example of context dependency (52). However, context dependency is more correctly defined as variation in net outcomes of an interaction due to stochastic shifts in biotic and abiotic conditions (18). This term is not inclusive of the normal predictable change in substrate conditions encountered by a host and its symbionts, such as that occurring in a tree over a generation of a bark beetle and its fungi.

Net outcomes are the sum total of effects of the interaction on partner fitness and determine whether an association can be considered a mutualism, a commensalism, or an antagonism. Even if a beneficial effect occurs at some point within a host generation, and if the net effect of the interaction overall is a reduction in either partner's fitness, the interaction cannot be considered a mutualism. In the case of $D$. frontalis, $O$. minus is not required by the bark beetle and indeed is unlikely to contribute to tree mortality when it is present. In addition, its effects on $D$. frontalis reproduction and survival are strongly negative and increase with increasing prevalence of the fungus within a tree. Indeed, effects of this fungus are so severe that once a particular threshold of phloem area colonized by $O$. minus in the tree is reached, bark beetle populations collapse $(37,61)$.

Ophiostoma minus is also unlikely to benefit the bark beetle through defense exhaustion. This fungus initiates only a small-to-moderate lesion response. Thus, for this fungus to rapidly stimulate defenses to the point that they are exhausted, high levels of fungal inoculation by attacking bark beetles are likely required. However, trees can be overwhelmed without the fungus and high levels of $O$. minus in a tree drastically reduce the host bark beetle's fitness, making this fungus an unlikely candidate to fulfill this role.

Additional indirect evidence that $O$. minus is not a mutualist of the bark beetle comes from studies on mites associated with $D$. frontalis. Tarsonemid mites phoretic on $D$. frontalis carry $O$. minus in structures called sporothecae $(10,16)$. The mites are involved in a nutritional mutualism with $O$. minus; feeding on the fungus results in high levels of mite productivity (62). The prevalence of $O$. minus in a tree colonized by $D$. frontalis is determined by the abundance of mites, which in turn is primarily driven by temperature $(38,61)$. When thermal conditions are favorable for mites, mite abundance increases and the prevalence of $O$. minus within the tree likewise increases (61). Once a particular threshold of area colonized by $O$. minus in the tree is reached, bark beetle populations decline. This fungus-driven decline in bark beetles can even result in the termination of outbreaks $(37,61)$.

A recent and fascinating discovery is that $D$. frontalis carries actinomycete bacteria that are antagonistic to $O$. minus $(1,87)$. Although the actinobacteria-bark beetle association is only peripherally understood, it would be difficult to reconcile the notion that $D$. frontalis would selectively carry a microbe antagonistic to a fungus on which it relies for tree killing. 
The $D$. frontalis-fungus system includes one of the most important tree-killing bark beetles in the world. The insect carries a pathogenic fungus, but fungi do not appear to play a role in tree killing or in exhausting tree defenses. This exemplifies the fact that strong fidelity to the $\mathrm{CP}$ for many decades has frustrated our understanding of the manner in which these interactions truly function. The real story has only begun to unfold now that researchers have been willing to consider alternative roles for fungal partners.

\section{Why are some fungi associated with bark beetles phytopathogenic?}

If phytopathogenicity is not required to aid bark beetle hosts in overcoming tree defenses, why do some fungal associates possess this quality? Perhaps a useful place to begin to investigate this question is to inspect fungal lifestyles and strategies and to consider how phytopathogenicity may be important to the fungi rather than to the bark beetle.

The fungi associated with tree-killing bark beetles must initially face hostile conditions as the bark beetles deliver them into a tree that is still living and able to defend itself. Pathogenicity may allow these fungi to survive in a living tree until defenses decline and the environment becomes more conducive to growth. In addition, pathogenicity may play a role in competition among the fungal associates (31). Pathogens would be more competitive early in the colonization process when tree tissues are still living, whereas more saprophytic species may become dominant later on.

Relative differences in pathogenicity likely play a substantial role in determining fungal community dynamics within a tree over time. At first glance, the multiple symbionts associated with a bark beetle host appear to occupy the same niche (they occur in the same place at the same time, use similar resources, and compete for the same hosts for dispersal). This should result in strong direct competition and selection for whichever species is most competitive. However, even slight differences in environmental tolerances and intrinsic vital properties (such as virulence and resource use) can alter niche hyperspace to the degree that several fungi can occupy different realized niches within a limited resource base. This effectively reduces competition and allows for coexistence between a number of different symbionts. For example, we know that the two fungi associated with D. ponderosae possess different temperature tolerances $(92,100)$. These differences determine which fungus is vectored by dispersing host bark beetles as temperatures fluctuate over a season and which fungus dominates within a tree during the developmental period of a bark beetle $(3,12$, 90). By growing at different temperatures, and thus at different times, the fungi may minimize competition with one another except within a narrow range of temperatures at which the growth of both fungi is equally supported. This separation in niches is most likely further attenuated through differential use of carbon and nitrogen sources within the tree (11).

Differences in relative virulence are also likely to play a role in the niche separation of these two fungi. G. clavigera, a common associate of $D$. ponderosae, is moderately virulent (100). It can grow in still-living host tissues containing defensive compounds and under the low-oxygen and highmoisture conditions that predominate in trees during the initial stages of bark beetle development (100). On the other hand, O. montium, also associated with this beetle, is only weakly virulent. It grows slowly during the initial stages of bark beetle development but proliferates rapidly once tree defenses have declined and oxygen content increases and moisture content decreases $(11,100)$.

Virulent fungi are often found with bark beetles that complete their entire development in living trees. In this case, high levels of virulence may be related to the need for these fungi to grow and survive in a defensive host that is continuously trying to kill them or to restrict their growth. These fungi must survive for up to a year under such conditions, until their vectors complete development 
and transport them to a new host. If these fungi did not exhibit relatively high levels of virulence, they would likely be killed or contained soon after entry into the tree.

\section{Summary points}

1. Symbioses between tree-killing bark beetles and ophiostomatoid fungi have been postulated to be mutualisms in which the fungi benefit through transport to new host trees and in return benefit the bark beetles by aiding in overwhelming tree defenses and/or killing the tree. The CP has driven most research on these symbioses, yet after decades of study, no conclusive evidence exists supporting this role for the fungi.

2. Several lines of indirect evidence strongly suggest that the $\mathrm{CP}$ is fundamentally flawed. These include the lack of consistency of virulent fungal associates with tree-killing bark beetles, the lack of correspondence between fungal growth in the host tree and the development of symptoms associated with a successful attack, and the ubiquity of similar associations of fungi with bark beetles that do not kill trees.

3. Nearly all focus on fungal phytopathogenicity has been on the importance of this characteristic to the bark beetle. However, we suggest that, rather than playing a supporting role for the host bark beetle (tree killing), phytopathogenicity performs an important role for the fungi that exhibit this characteristic, particularly in mediating competitive interactions with other fungi and supporting survival and efficient resource capture in living, defensive trees.

\section{Future issues}

1. An important first step will be to broaden our approach to include symbioses between fungi and non-tree-killing bark beetle species. It will be informative to investigate whether interactions among non-tree-killing bark beetles and fungi are similar or inherently different from those occurring between tree-killing species and fungi. In addition, it will be important to understand why species of related fungi can have profoundly different effects on the host insect. For instance, there is a need to understand why some Ophiostoma species are mutualists and others are commensals or antagonists.

2. An understanding of how biotic and abiotic factors affect the relative prevalence of the fungi with a host over time will be critically important in understanding the dynamics of these associations. Fungal dynamics must surely also affect bark beetle population dynamics, and understanding how this occurs will be important.

3. Powerful molecular tools are now available to aid in our understanding of the evolution and function of these symbioses. Also, mutualism theory has seen amazing advancements in just the past few years. Some of these powerful new tools should be used to investigate bark beetle-fungus systems.

4. In a review of bark beetle-fungus interactions, Stewart Whitney, an early pioneer of this topic, suggested that "Occam's razor might not be sharp enough to slice through the jungle of information and the simplest hypothesis may merely be simplest in a complex series of hypotheses" (107). Bark beetle-fungus symbioses are complex, and the role that the fungi play in the lives of the bark beetles remains substantially clouded. We have argued here that the $\mathrm{CP}$, although a comfortable hypothesis, is strongly flawed. By seeking alternatives rather than a convenient explanation, we expect that many fascinating and previously unimagined roles for the fungi in their relationships with bark beetles will emerge. 


\section{Disclosure statement}

The authors are not aware of any affiliations, memberships, funding, or financial holdings that might be perceived as affecting the objectivity of this review.

\section{Acknowledgments}

Many colleagues in various parts of the world, and too numerous to name individually, have contributed to interesting discussions and debates regarding the role of fungi in their symbiosis with bark beetles. We are grateful for the views that they have shared with us, and although some will not agree with all our arguments, we hope that these will stimulate a new wave of understanding of a fascinating and long-debated topic. We also appreciate the financial support of the DST/NRF Center of Excellence in Tree Health Biotechnology, South Africa.

\section{Literature Cited}

1. Aanen DK, Slippers B, Wingfield MJ. 2009. Biological pest control in beetle agriculture. Trends Microbiol. 17:179-82

2. Abraham L, Hoffman B, Gao Y, Breuil C. 1998. Action of Ophiostoma piceae proteinase and lipase on wood nutrients. Can. J. Microbiol. 44:698-701

3. Adams AS, Six DL. 2007. Temporal variation in mycophagy and prevalence of fungi associated with developmental stages of the mountain pine beetle, Dendroctonus ponderosae (Coleoptera: Scolytinae, Curculionidae). Environ. Entomol. 36:64-72

4. Anderbrandt O. 1988. Survival of parent and brood bark beetles, Ips typographus, in relation to size, lipid content and reemergence or emergence day. Physiol. Entomol. 13:121-29

5. Ayres MP, Wilkens RT, Ruel JJ. 2000. Nitrogen budgets of phloem-feeding bark beetles with and without symbiotic fungi. Ecology 81:2198-210

6. Barras SJ. 1970. Antagonism between Dendroctonus frontalis and the fungus Ceratocystis minor. Ann. Entomol. Soc. Am. 63:1187-90

7. Barras SJ, Perry T. 1971. Leptographium terebrantis sp. nov. associated with Dendroctonus terebrans in loblolly pine. Mycopathologia 43:1-10

8. Beaver RA. 1989. Insect-fungus relationships in the bark and ambrosia beetles. In Insect-Fungus Interactions, ed. N Wilding, NM Collins, PM Hammond, JF Webber, pp. 121-43. London: Academic

9. Berryman AA. 1972. Resistance of conifers to invasion by bark beetle-fungus associations.

Bioscience 22:598-602

10. Blackwell M, Bridges JR, Moser JC, Perry TJ. 1986. Hyperphoretic dispersal of a Pyxidiophora anamorph. Science 232:993-95

11. Bleiker K, Six DL. 2007. Dietary benefits of fungal associates to an eruptive herbivore: potential implications of multiple associates on host population dynamics. Environ. Entomol. 36:1384-96 
12. Bleiker KP, Six DL. 2008. Competition and coexistence in a multi-partner mutualism: interactions between two fungal symbionts of the mountain pine beetle in beetle-attacked trees. Microbial Ecol. 57:191-202

13. Bleiker KP, Six DL. 2009. Effects of water potential and solute on the growth and interactions of two fungal symbionts of the mountain pine beetle. Mycol. Res. 113:3-15

14. Bramble WC, Holst EC. 1940. Fungi associated with Dendroctonus frontalis in killing shortleaf pines and their effects on conduction. Phytopathology 30:881-99

15. Bridges R. 1983. Mycangial fungi of Dendroctonus frontalis (Coleoptera: Scolytidae) and their relationship to beetle population trends. Environ. Entomol. 12:858-61

16. Bridges RJ, Moser JC. 1983. Role of two phoretic mites in the transmission of bluestain fungus, Ceratocystis minor. Ecol. Entomol. 8:9-12

17. Bridges RJ, Nettleton WA,Connor MD. 1985. Southern pine beetle (Coleoptera: Scolytidae) infestations without the bluestain fungus, Ceratocystis minor. J. Econ. Entomol. 78:325-27

18. Bronstein JL. 1994. Conditional outcomes in mutualistic interactions. Trends Ecol. Evol. 9:21417

19. Christiansen E. 1985. Ips/Ceratocystis infection of Norway spruce: What is a deadly dosage? J. Appl. Entomol. 99:6-11

20. Christiansen E, Solheim H. 1990. The bark beetle-associated blue stain fungus Ophiostoma polonicum can kill various spruces and Douglas fir. Eur. J. For. Pathol. 20:436-46

21. Christiansen E, Waring RH, Berryman AA. 1987. Resistance of conifers to bark beetle attack: searching for general relationships. For. Ecol. Manag. 22:89-106

22. Cook SP, Hain FP. 1985. Qualitative examination of hypersensitive response of loblolly pine, Pinus taeda L., inoculated with two fungal associates of the southern pine beetle, Dendroctonus frontalis Zimmermann (Coleoptera: Scolytidae). Environ. Entomol. 14:396-400

23. Coppedge BR, Stephen FM, Felton GW. 1995. Variation in female southern pine beetle size and lipid content in relation to fungal associates. Can. Entomol. 127:145-54

24. Craighead FC. 1928. The interrelation of tree-killing bark beetles (Dendroctonus) and blue stains. J. For. 26:886-87

25. De Angelis JD, Hodges JD, Nebeker TE. 1986. Phenolic metabolites of Ceratocystis minor from laboratory cultures and their effects on transpiration in loblolly pine seedling. Can. J. Bot. 64:15155

26. Fernandez MMF, Garcia AE, Lieutier F. 2004. Effects of various densities of Ophiostoma ips inoculations on Pinus sylvestris in north-western Spain. For. Pathol. 34:213-23

27. Filip GM, Schmitt CL, Scott DW,Fitzgerald SA. 2006. Understanding and defining mortality in western conifer forests. West. J. Appl. For. 22:105-15 
28. Fox JW, Wood DL, Akers PP, Partmeter JR Jr. 1992. Survival and development of Ips paraconfusus Lanier (Coleoptera: Scolytidae) reared axenically and with tree pathogenic fungi vectored by cohabiting Dendroctonus species. Can. Entomol. 124:1157-67

29. Francheschi VR, Krokene P, Christiansen E, Krekling T. 2005. Anatomical and chemical defenses of conifer bark against bark beetle and other pests. New Phytol. 167:353-75

30. Haberkern KE, Illman BL, Raffa KF. 2002. Bark beetles and associates colonizing white spruce in the Great Lakes region. Can. J. For. Res. 32:1137-50

31. Harrington TC. 1993. Diseases of conifers caused by species of Ophiostoma and Leptographium. See Ref. 111, pp. 161-72

32. Harrington TC. 2005. Ecology and evolution of mycophagous bark beetles and their fungal partners. In Insect-Fungal Associations: Ecology and Evolution, ed. FE Vega, M Blackwell, pp. 257-91. Oxford: Oxford Univ. Press

33. Harrington TC, Wingfield MJ. 1998. The Ceratocystis species on conifers. Can. J. Bot. $17: 1446-57$

34. Hemingway RW, McGraw GW, Barras SJ. 1977. Polyphenols in Ceratocystis minor-infected Pinus taeda: fungal metabolites, phloem and xylem phenols. Agric. Food Chem. 25:717-22

35. Hetrick LA. 1949. Some overlooked relationships of the southern pine beetle. J. Econ. Entomol. 42:466-69

36. Hobson KR, Parmeter JR Jr, Wood DL. 1994. The role of fungi vectored by Dendroctonus brevicomis LeConte (Coleoptera: Scolytidae) in occlusion of ponderosa pine xylem. Can. Entomol. $126: 277-82$

37. Hofstetter RW, Cronin J, Klepzig KD, Moser JC, Ayres MP. 2006. Antagonisms, mutualisms and commensalisms affect outbreak dynamics of the southern pine beetle. Oecologia 147:679-91

38. Hofstteter RW, Dempsey TD, Klepzig KD, Ayres MP. 2007. Temperature-dependent effects on mutualistic, antagonistic and commensalistic interactions among insects, fungi and mites. Community Ecol. 8:47-56

39. Hofstetter RW, Klepzig KD, Moser JC, Ayres MP. 2006. Seasonal dynamics of mites and fungi and their effects on the southern pine beetle. Environ. Entomol. 35:22-30

40. Hofstetter RW, Mahfouz JB, Klepzig KD, Ayres MP. 2005. Effects of tree phytochemistry on the interactions among endophloedic fungi associated with the southern pine beetle. J. Chem. Ecol. $31: 539-57$

41. Hornvedt R, Christiansen E, Solheim H, Wand S. 1983. Artificial inoculation with Ips typographus-associated blue-stain fungi can kill healthy Norway spruce trees. Medd. Nor. Inst. Skogforsk 38:1-20

42. Hsiau P-TW, Harrington TC. 2003. Phylogenetics and adaptations of basidiomycetous fungi fed upon by bark beetles (Coleoptera: Scolytidae). Symbiosis 34:111-31 
43. Jacobs K, Wingfield MJ. 2001. Leptographium species: tree pathogens, insect associates, and agents of blue-stain. St. Paul: Am. Phytopathol. Soc. Press

44. Jankowiak R. 2005. Fungi associated with Ips typographus on Picea abies in southern Poland and their succession into the phloem and sapwood of beetle-infested trees and logs. For. Pathol. $35: 37-55$

45. Jankowiak R. 2006. Fungi associated with Tomicus piniperda in Poland and assessment of their virulence using Scots pine seedlings. Ann. For. Sci. 63:801-8

46. Kim J-J, Plattner A, Lim YW, Breuil C. 2008. Comparison of two methods to assess the virulence of the mountain pine beetle associate, Grosmannia clavigera, to Pinus contorta. Scand. J. For. Res. 23:98-104

47. Kirisits T. 2004. Fungal associates of European bark beetles with special emphasis on the ophiostomatoid fungi. In Bark and wood boring insects in living trees in Europe, a synthesis, ed. F Lieutier, KR Day, A Battisti, J-C Gregoire, HF Evans, pp. 181-236. Dordrecht, Nether.: Kluwer Acad.

48. Klepzig KD, Flores-Otero J, Hofstetter RW, Ayres MP. 2004. Effects of available water on growth and competition of southern pine beetle associated fungi. Mycol. Res. 108:183-88

49. Klepzig KD, Moser JC, Lombardero FJ, Hofstetter RW, Ayres MP. 2001. Symbiosis and competition: complex interactions among beetles, fungi and mites. Symbiosis 30:83-96

50. Klepzig KD, Raffa KF, Smalley EB. 1991. Association of an insect-fungal complex with red pine decline in Wisconsin. For. Sci. 37:1119-39

51. Klepzig KD, Robison DJ, Fowler G, Minchin PR, Hain FP, Allen HL. 2005. Effects of mass inoculation on induced oleoresin response in intensively managed loblolly pine. Tree Physiol. 25:681-88

52. Klepzig KD, Six DL. 2004. Context dependency in bark beetle-fungal symbioses: complex interactions in complex associations. Symbiosis 37:189-205

53. Klepzig KD, Wilkens RT. 1997. Competitive interactions among symbiotic fungi of the southern pine beetle. Appl. Environ. Microbiol. 63:621-27

54. Kopper BJ, Klepzig KD, Raffa KF. 2004. Components of antagonism and mutualism in Ips pini-fungal interactions: relationship to a life history of colonizing highly stressed and dead trees. Environ. Entomol. 33:28-34

55. Krokene P, Solheim H. 1996. Fungal associates of five bark beetles species colonizing Norway spruce. Can. J. For. Res. 26:2115-22

56. Langstrom B, Solheim H, Hellqvist C, Gref R. 1993. Effects of pruning young Scots pines on host vigor and susceptibility to Leptographium wingfieldii and Ophiostoma minus, two blue stain fungi associated with Tomicus piniperda. Eur. J. For. Pathol. 23:400-15

57. Lee S, Kim J-J, Breuil C. 2006. Fungal diversity associated with the mountain pine beetle, Dendroctonus ponderosae and infested lodgepole pines in British Columbia. Fungal Divers. 22:91105 
58. Lieutier F. 2002. Mechanisms of resistance in conifers and bark beetle attack strategies. In Mechanism and deployment of resistance in trees to insects, ed. MR Wagner, KM Clancy, F Lieutier, TD Paine, pp. 31-77. Dordrecht, Nether.: Kluwer Acad.

59. Lieutier F. 2004. Host resistance to bark beetles and its variations. In Bark and wood boring insects in living trees in Europe, a synthesis, ed. F Lieutier, KR Day, A Battisti, J-C Gregoire, HF Evans, pp. 135-80. Dordrecht, Nether.: Kluwer Acad.

60. Lieutier F, Yart A, Salle A. 2009. Stimulation of tree defenses by ophiostomatoid fungi can explain attack success of bark beetles in conifers. Ann. For Sci. 66:801

61. Lombardero MJ, Ayres MP, Hofstetter RW, Moser JC, Klepzig KD. 2003. Strong indirect interactions of Tarsonemus mites (Acarina: Tarsonemidae) and Dendroctonus frontalis (Coleoptera: Scolytidae). Oikos 102:243-52

62. Lombardero MJ, Klepzig KD, Moser JC, Ayres MP. 2000. Biology, demography and community interactions of Tarsonemus (Acarina: Tarsonemidae) mites phoretic on Dendroctonus frontalis (Coleoptera: Scolytidae). Agric. For. Entomol. 2:193-202

63. Mathiesen-Kaarik A. 1960. Studies on the ecology, taxonomy, and physiology of Swedish insect associated blue stain fungi, especially the genus Ceratocystis. Oikos 11:1-25

64. Matsuya H, Kaneko S, Yamaoka Y. 2003. Comparative virulence of blue-stain fungi isolated from Japanese red pine. J. For. Res. 8:83-88

65. Molnar AC. 1965. Pathogenic fungi associated with a bark beetle on alpine fir. Can. J. Bot. 43:563-70

66. Mullick DB. 1977. The nonspecific nature of defense in bark and wood during wounding, insect and pathogen attack. Rec. Adv. Phytochem. 11:359-441

67. Mulock P, Christiansen E. 1986. The threshold of successful attack by Ips typographus on Picea abies: a field experiment. For. Ecol. Manag. 14:125-32

68. Nelson RM. 1934. Effect of bluestain fungi on southern pines attacked by bark beetles. Phytopathol. Z. 7:327-53

69. Paine TD. 1984. Seasonal response of ponderosa pine to inoculation of the mycangial fungi of the western pine beetle. Can. J. Bot. 62:551-55

70. Paine TD, Raffa KF, Harrington TC. 1997. Interactions among scolytid bark beetles, their associated fungi, and live host conifers. Annu. Rev. Entomol. 42:179-206

71. Paine TD, Stephen FM. 1987. Response of loblolly pine to different inoculum doses of Ceratocystis minor, a blue-satin fungus associated with Dendroctonus frontalis. Can. J. Bot. 65:2093-95

72. Paine TD, Stephen FM, Cates RG. 1988. Phenology of an induced response in loblolly pine following inoculation of fungi associated with the southern pine beetle. Can. J. For. Res. 18:155662 
73. Parmeter JR Jr, Slaughter GW, Chen M, Wood DL. 1992. Rate and depth of sapwood occlusion following inoculation of pines with bluestain fungi. For. Sci. 38:34-41

74. Parmeter JR Jr, Slaughter GW, Chen M-M, Wood DL, Stubbs HA. 1989. Single and mixed inoculations of ponderosa pine with fungal associates of Dendroctonus spp. Phytopathology 79:768-72

75. Popp MP, Johnson JD, Lesney MS. 1995. Characterization of the induced response of slash pine to inoculation with bark beetle vectored fungi. Tree Physiol. 15:619-23

76. Raffa KF, Berryman AA. 1983. Physiological aspects of lodgepole pine wound responses to a fungal symbiont of the mountain pine beetle. Can. Entomol. 115:723-34

77. Raffa KF, Phillips TW, Salom SM. 1993. Strategies andmechanisms of host colonization by bark beetles. In Beetle-pathogen interactions in conifer forests, ed. T Schowalter, G Filip, pp. 10228. San Diego, CA: Academic

78. Raffa KF, Smalley EB. 1995. Interaction of preattack and induced monoterpene concentrations in conifer defense against bark beetle-fungal complexes. Oecologia 102:285-95

79. Rane KK, Tattar TA. 1987. Pathogenicity of blue stain fungi associated with Dendroctonus terebrans. Plant Dis. 71:879-83

80. Reid RW,Whitney HS, Watson JA. 1967. Reactions of lodgepole pine to attack by Dendroctonus ponderosae Hopkins and bluestain fungi. Can. J. Bot. 45:1115-26

81. Reynolds KM. 1992. Relations between activity of Dendroctonus rufipennis Kirby on Lutz spruce and blue stain associate Leptograhium abietinum (Peck)Wingfield. For. Ecol. Manag. 47:7186

82. Rice A, Thormann MN, Langor DW. 2007. Virulence of and interactions among mountain pine beetle associated blue stain fungi on two pine species and their hybrids in Alberta. Can. J. Bot. $85: 316-23$

83. Romon P, Zhou X, Iturrondobeitia JC, Wingfield MJ, Goldarazena A. 2007. Ophiostoma species (Ascomycetes: Ophiostomatales) associated with bark beetles (Coleoptera: Scolytinae) colonizing Pinus radiata in northern Spain. Can. J. Microbiol. 53:756-67

84. Ross DW, Fenn P, Stephen FM. 1992. Growth of southern pine beetle associated fungi in relation to the induced wound response in loblolly pine. Can. J. For. Res. 22:1851-59

85. Ross DW, Solheim H. 1997. Pathogenicity of Douglas fir of Ophiostoma pseudotsugae and Leptographium abietinum, fungi associated with the Douglas fir beetle. Can. J. For. Res. 27:39-43

86. Salle A, Monclus R, Yart A, Garcia J, Romary P, Lieutier F. 2005. Fungal flora associated with Ips typographus: frequency, virulence, and ability to stimulate the host defense reaction in relation to insect population levels. Can. J. For. Res. 35:365-73

87. Scott JJ, Oh D-C, Yuceer MC, Klepzig KD, Clardy J, Currie CR. 2008. Bacterial protection of beetle fungus mutualism. Science 322:63 
88. Six DL. 2003. Bark beetle-fungus symbioses. In Insect symbiosis, ed. K Bourtzis, T Miller, pp. 97-114. Boca Raton, FL: CRC Press

89. Six DL, Bentz BJ. 2003. Fungi associated with the North American spruce beetle, Dendroctonus rufipennis. Can. J. For. Res. 33:1815-20

90. Six DL, Bentz BJ. 2007. Temperature determines the relative abundance of symbionts in a multipartite bark beetle-fungus symbiosis. Microb. Ecol. 54:112-18

91. Six DL, Klepzig KD. 2004. Dendroctonus bark beetles as model systems for the study of symbiosis. Symbiosis 37:207-32

92. Six DL, Paine TD. 1997. Ophiostoma clavigerum is the mycangial fungus of the Jeffrey pine beetle, Dendroctonus jeffreyi. Mycologia 89:858-66

93. Six DL, Paine TD. 1998. Effects of mycangial fungi and host tree species on progeny survival and emergence of Dendroctonus ponderosae (Coleoptera: Scolytidae). Environ. Entomol. 27:1393401

94. Six DL, Paine TD. 1999. A phylogenetic comparison of ascomycete mycangial fungi and Dendroctonus bark beetles (Coleoptera: Scolytidae). Ann. Entomol. Soc. Am. 92:159-66

95. Solheim H. 1986. Species of Ophiostomataceae isolated from Picea abies infested by the bark beetle Ips typographus. Nord. J. Bot. 6:199-207

96. Solheim H. 1988. Pathogenicity of some Ips typographus-associated blue-stain fungi to Norway spruce. Medd. Nor. Inst. Skoforsk 40:1-11

97. Solheim H. 1991. Oxygen deficiency and spruce resin inhibition of growth of blue stain fungi associated with Ips typographus. Mycol. Res. 95:1387-92

98. Solheim H. 1992. The early stages of fungal invasion in Norway spruce infested by the bark beetle Ips typographus. Can. J. Bot. 70:1-5

99. Solheim H. 1995. Early stages of blue-stain fungus invasion of lodgepole pine sapwood following mountain pine beetle attack. Can. J. Bot. 73:70-74

100. Solheim H, Krokene P. 1998. Growth and virulence of mountain pine beetle associated bluestain fungi, Ophiostoma clavigerum and Ophiostoma montium. Can. J. Bot. 76:561-66

101. Solheim H, Langstrom B. 1991. Blue-stain fungi associated with Tomicus piniperda in Sweden and preliminary observations on their pathogenicity. Ann. Sci. For. 48:149-56

102. Solheim H, Safranyik L. 1997. Pathogenicity to Sitka spruce of Ceratocystis rufipenni and Leptographium abietinum, blue stain fungi associated with the spruce bark beetle. Can. J. For. Res. 27:1336-41

103. Spatafora JW, Blackwell M. 1994. The polyphyletic origins of ophiostomatoid fungi. Mycol. Res. 98:1-9

104. Viiri H. 1997. Fungal associates of the spruce bark beetle Ips typographus L. (Coleoptera: Scolytidae) in relation to different trapping methods. J. Appl. Entomol. 121:529-33 
105. Viiri H, Lieutier F. 2004. Ophiostomatoid fungi associated with the spruce bark beetle, Ips typographus, in three areas in France. Ann. For. Sci. 61:215-19

106. Vite JP. 1961. Influence of water supply on oleoresin exudation pressure and resistance to bark beetle attack in Pinus ponderosa. Contrib. Boyce Thompson Inst. 21:37-66

107. Von Schrenk H. 1903. The "bluing" and the "red rot" of the western yellow pine with special reference to the Black Hills Forest Reserve. US Bur. Plant. Ind. Bull. 36:1-40

108. Whitney HS, Bandoni RJ, Oberwinkler F. 1987. Entomocorticium dendroctoni gen. et. sp. nov. (Basidiomycotina), a possible nutritional symbiote of the mountain pine beetle in lodgepole pine in British Columbia. Can. J. Bot. 65:95-102

109. Whitney HS, Cobb FW. 1972. Non-staining fungi associated with the bark beetle Dendroctonus brevicomis (Coleoptera: Scolytidae) on Pinus ponderosa. Can. J. Bot. 50:1943-45

110. Wingfield MJ. 1986. Pathogenicity of Leptographium procerum and L. terebrantis on Pinus strobus seedlings and established trees. Eur. J. For. Pathol. 16:299-308

111. Wingfield MJ, Seifert KA, Webber JF, eds. 1993. Ceratocystis and Ophiostoma: Taxonomy Ecology and Pathogenicity. St. Paul: Am. Phytopathol. Soc. Press

112. Wood DL. 1982. The role of pheromones, kairomones, and allomones in the host selection and colonization behavior of bark beetles. Annu. Rev. Entomol. 27:411-46

113. Wood S. 1982. The bark and ambrosia beetles of North and Central America (Coleoptera: Scolytidae): a taxonomic monograph. Great Basin Nat. Mem. 6. Provo, UT: Brigham Young Univ. Press. 1359 pp.

114. Yamaoka Y, Hiratsuka Y, Maruyama PJ. 1995. The ability of Ophiostoma clavigerum to kill mature lodgepole pine trees. Eur. J. For. Pathol. 25:401-4

115. Yamaoka Y, Swanson RH, Hiratsuka Y. 1990. Inoculation of lodegepole pine with four blue stain fungi associated with mountain pine beetle, monitored by a heat pulse velocity (HPV) instrument. Can. J. For. Res. 20:31-36

116. Zhou XD, de Beer ZW,Wingfield BD, Wingfield MJ. 2001. Ophiostomatoid fungi associated with three pine-infesting bark beetles in South Africa. Sydowia 53:290-300

117. Zipfel RD, de Beer ZW, Jacobs K, Wingfield BD, Wingfield MJ. 2006. Multigene phylogenies define Ceratocystiopsis and Grosmannia distinct from Ophiostoma. Stud. Mycol. 55:75-97 